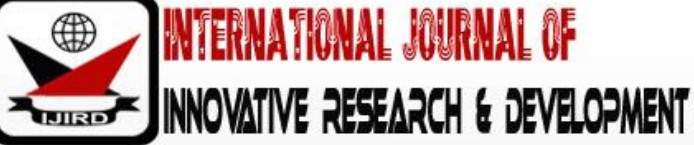

ISSN 2278 - 0211 (Online)

\section{Improved Cookstoves and User Preferences of Rural Women in Ondo State, Nigeria: Estimates from Random Utility Maximization Model}

\author{
Oyenike Olumide Ojo \\ Research Fellow, Department of Forest Economics \& Extension Services, \\ Forestry Research Institute of Nigeria, Nigeria \\ Dr. David Olufemi Awolala \\ Lecturer, Department of Agricultural and Resource Economics, \\ Federal University of Technology Akure, Ondo State, Nigeria \\ Sylvester Oludare 0J0 \\ Professor, Department of Agricultural \& Resource Economics Department \\ Federal University of Technology Akure, Ondo State, Nigeria
}

\begin{abstract}
:
Cleaner and more efficient cookstoves have the potential to generate social, economic, health and environmental benefits. Rural women will only purchase improved cookstoves that meet their cooking needs and priorities. The study analysed choice preferences of improved cookstoves by rural women households in the study area. Results from primary data shows that $77.5 \%$ of respondents are willing to pay for improved cookstove while $22.5 \%$ are not willing. While $43.8 \%$ are willing to pay for Envirofit, 19.1\% went for KIKE Green Cookstove and 14.6\% went for charcoal cookstove among those who are willing to buy. The logistic regression model estimates show that source of information on benefits was a significant factor influencing rural women' decision on the purchase and uptake of clean cookstoves. Formal means of communication was effective as expected in creating required awareness among the rural people. Hence, there is need to increase awareness level on the opportunity cost of health risks of the continual use of traditional cookstoves. There is no relationship between awareness and willingness to pay for improved cookstoves, however, there is a significant relationship between health effect of traditional stoves and willingness to buy improved cookstove.
\end{abstract}

Keywords: Indoor-air quality, Preference, Rural women, improved cook stoves, Willingness to pay

\section{Introduction}

Energy is one of the most important items for human survival apart from air, water and food. It is required for cooking, lighting, heating, boiling and other various domestic needs. Rural population largely depend on the traditional sources of energy in meeting their domestic energy demands while urban population depend essentially on charcoal and fossil fuels. However, high level of poverty and other socio-economic problems constrains both rural and urban population from access to adequate, reliable and clean energy sources for domestic purposes (Momodu, 2013).

Of all domestic fuels in Nigeria, fuelwood remains the commonest partly due to its accessibility, affordability, convenience, tradition and vegetative distribution as other sources namely domestic gas, wind energy, kerosene, solar energy and electricity are either uncommon, modern, costly, sophisticated or required high levels of education and technology to explore, exploit, refine, distribute, store, utilized and maintained (Akut, 2008). Demand for traditional fuel therefore places significant pressure on local forests and woodlands, contributing to deforestation, soil erosion and desertification. Oftentimes, the need for wood is so great that reforestation attempts of badly degraded regions prove impossible because even young trees are rapidly been harvested for cooking fuelwood or charcoal production. In the most severely affected regions, the poorest fuel sources, animal manures, grasses, crop residues, roots and shrubs are also harvested (FAO, 2013).

In the developing countries, nearly 3 billion people rely on traditional cooking methods such as an open fire or basic cookstoves, using solid fuels such as wood, charcoal, crop residues and animal dung (GACC, 2011). An energy access assessment across many developing countries reveals that 600 million of this population live in the Sub-Saharan Africa (SSA) where access to modern fuels is as low as $17 \%$, while $69 \%$ of the population rely on wood as their primary cooking fuel (UNDP/ WHO, 2009).

In the efforts by the industrialized economies to mitigate climate change, efforts are being made at reducing Carbon dioxide $\left(\mathrm{CO}_{2}\right)$ emissions by $50 \%$ or more by 2050 . Since $\mathrm{CO}_{2}$ is the most significant and prevalent greenhouse gas 
released by human activities, and emitted mostly from burning of fossil fuels such as coal, oil and natural gas. Many technological solutions therefore exist for reducing greenhouse gas emissions (Climate Change Summary, 2014).

The Nigerian Alliance for Clean Cookstoves commenced a collaborative venture with its foreign ally "Global Alliance" and the pro-poor social enterprise "Wonderbag" seeks to expand access to clean cooking energy to Nigerian households. Nigerian alliance collaborated with the Global Alliance to ensure adequate public awareness is created toward using cookstove, especially the rural and semi-urban households that normally depend on kerosene and fuelwood for their cooking (Eleri et al., 2011). The public private partnership Alliance seeks to deliver 10 million improved cookstoves to Nigerian homes and institutions by 2020 . Wonderbag seeks to address energy-food poverty, empower women, and create sustainable communities living in balance with the environment. Wonderbag brings innovation and diversity to the range of safe and cost-effective cooking options available to Nigerian households (World Bank, 2012).

\section{Impacts of Carbon Emissions on People and Environment}

An estimated 3 billion people cook with traditional stoves worldwide. These stoves generally consist of open fire which produces harmful emissions known to cause fatal illnesses. Traditional stoves claim 1.6 million lives each year and death of more under-5 age children than any other single cause. In addition, widespread land degradation and deforestation have resulted from inefficient fuel consumption of traditional stoves (Birzer et al., 2013).

There are increasing evidences that Carbon dioxide $\left(\mathrm{CO}_{2}\right)$ emissions is a major causal agent of acute respiratory infections, chronic obstructive pulmonary disease, lung cancer, tuberculosis, nasopharyngeal and laryngeal cancers, and asthma. It is ranked as the fourth most important cause of loss of a healthy life (Disability-Adjusted Life Year, DALYs) in developing countries (Ezzati and Baris, 2007). Women and children are particularly the most affected by indoor-air pollution especially because usually spent most times in the cooking area or home environment much longer than other family members (Menya et al., 2013).

Ityavyar and Thomas (2013) concluded that environmental problems in Nigeria are diverse in nature, and are caused by man's interaction with nature (environment) for exploits in a number of ways especially in cities where industrial activities predominate, and rural areas where agriculture thrives. These problems are a consequence of environmental pollution which also degenerates into environmental degradation and several other hazards such as widespread epidemics, depletion of natural habitats, and therefore impede the socio-economic development of Nigeria as an economy. Eleri (2013) further expressed that smoke from cooking fire causes 95,300 deaths in Nigeria. Poor families using three-stone fire spend much of the food budgets on buying fuelwoods and charcoals while others spend hours collecting wood. Inefficiency in the combustion of wood raises the cost of cooking for the poor and contributes to intense deforestation. Enhancing efficiency in biomass energy use will address health, poverty and environment challenges and create a market of over N300 billion in new cookstove alternatives.

In order to reduce the risk of ever-increasing air pollution and ill-health related to exposure to carbon, there is need to reduce how much carbon dioxide $\left(\mathrm{CO}_{2}\right)$ emitted which has led to the design of carbon clean cooking mechanisms, otherwise called improved cookstoves. Improved cookstoves could reduce in $\mathrm{CO}_{2}$ emissions from burning fuelwoods, thus reducing risk of physical abuse from gathering biomass fuels usually experience by women and children, lowering expenditure on fuelwoods and charcoal thereby increasing households' disposable income, reducing time and increase productivity from less fuel gathering, reducing tree, shrub and forest losses thereby promoting healthier indoor environments for rural dwellers. Rather than being simply designed to save fuelwoods, improved cookstoves addresses a comprehensive set of issues from local health and environmental implications to global impacts associated with Greenhouse Gas (GHG) emissions (Masera et al., 2005).

\section{Indoor-Air Quality Improvements and Technologies}

Over $40 \%$ of the world's population still burns various forms of biomass such as wood, dung, charcoal, crop residues, or coal as cooking fuel. They cook over open fires or on rudimentary cookstoves. This way of cooking emits harmful smoke that causes range of deadly chronic and acute health effects. Low carbon technologies have a vital role to play as important step towards achieving a green economy. Such technologies have potential to reduce the carbon intensity of processes at every stage of the energy supply chain from low carbon energy generation, through storage and transmission, to end-user efficiency. In doing so, carbon-dioxide emissions $\left(\mathrm{CO}_{2}\right)$ will be reduced (GACC, 2013). Many clean energy products such as improved cookstoves, solar home systems and lanterns, biomass briquettes, biogas and wind turbines are readily available (Clough and Rai, 2012).

Clean energy cookstoves were primarily designed to reduce Indoor-Air Pollution (IAP) emissions, and improved fuel and heat efficiency were supplementary benefits. Existing improved cookstoves and cleaner fuels, if deployed at scale, could save millions of lives, empower women, create opportunities for the poor, and reduce negative environmental impacts. Using less fuel which reduces time spent in fuelwood collections, it can allow more time to engage in positive income-generating activities, and pursue other important endeavours (GACC, 2013).

Globally, people use a variety of cookstoves and fuels to meet their daily cooking needs. Clean, efficient, durable, safe, and affordable stoves along with clean fuels and other products like chimneys, and heat retention cookers are central to most solutions to the health, environmental and other risks inherent in cooking with open fires. Cooking with clean fuels is the commonest way to achieve the sustainable health and green climate benefits. Advanced clean cookstoves in which solid biomass must be used are most likely to result into significant health and climate benefits. Some of the best examples of cookstove technologies have been designed as follows: 
Charcoal cookstove consists of a ceramic liner in a metal cladding. The ceramic liner protects the outer metal structure from deterioration by the fire. It provides a better insulation compared to the traditional all-metal charcoal stoves, with higher efficiency, hotter flame, and improved combustion. Charcoal stoves emit little particulate matter (visible smoke) but can have considerable carbon-monoxide (CO) emissions (GACC, 2013).

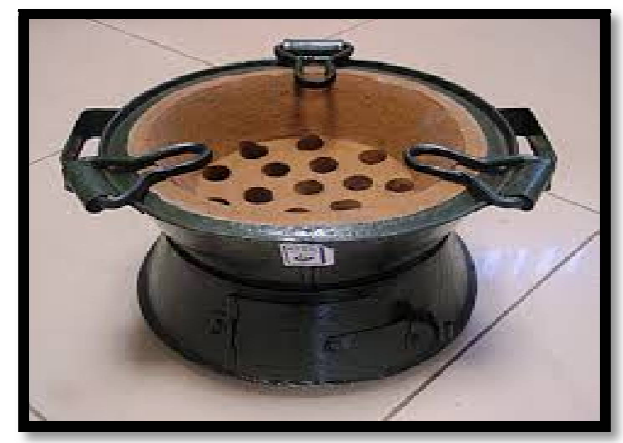

Figure 1: Improved Charcoal Cookstove

\subsection{KIKE Green Cookstove}

Kike Green Cookstove is made entirely of long-lasting special baked stainless-steel and uses ethanol gel fuel. It provides a significant health benefit to families otherwise dependent on dirty solid fuels such as kerosene, wood, dung, crop residues, charcoal, and coal by eliminating dangerous smoke and gases from home. The KIKE Green Cook dramatically reduces greenhouse gases and soot (black carbon) emissions by reducing wood use and deforestation.

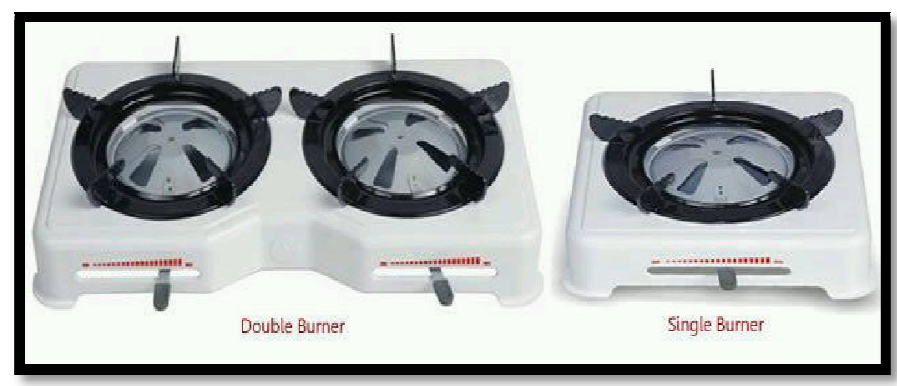

Figure 2: KIKE Green Cookstove

\subsection{Rocket Stove}

Rocket Stove uses a small-diameter wood fuel and burn in a simple high-temperature combustion chamber containing a vertical chimney and a secondary air supply which ensures almost complete combustion prior to flames reaching the cooking surface.

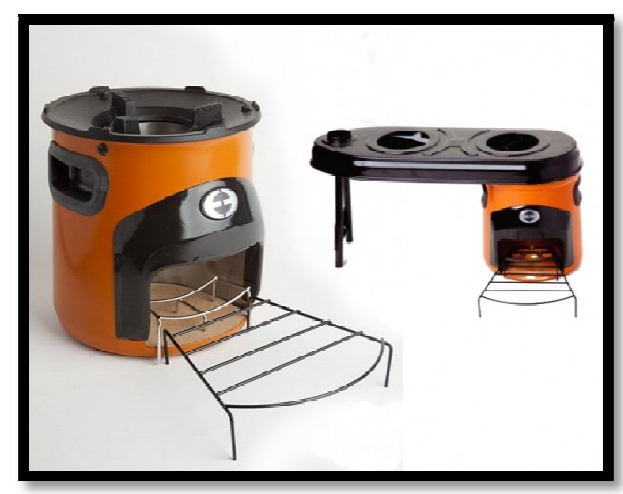

Figure 3: Rocket Stove

\subsection{Envirofit Cookstove}

The cookstove has a large vertical cylinder that holds a pot and an opening at the bottom to feed the combustible biomass to cook a meal or pasteurize drinking water. This cookstove burn biomass (wood, crop waste, dried animal dung) reduce fuel usage by $50 \%$ as compared with other stoves or open fire, and decreases cooking times by $40 \%$, thus reduces indoor-air pollution by $80 \%$. 


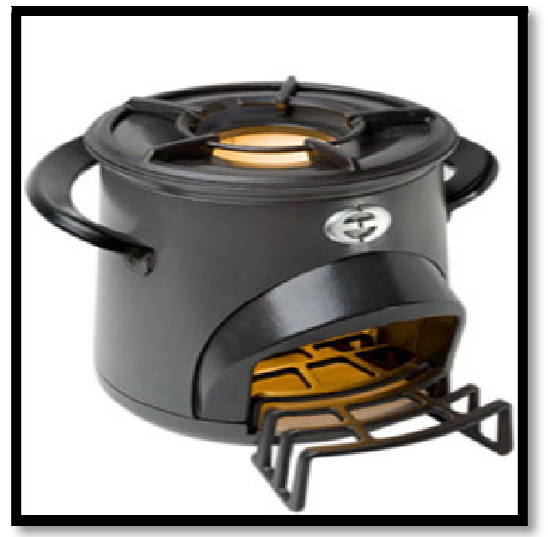

Figure 4: Envirofit Cookstove

The depletion of forest resources increases rural households' burdens, especially for women and children who are often responsible for meeting households' food and fuel needs. Providing cleaner and more efficient alternatives to traditional cooking stoves and fuels can enable women have some free time to engage more in productive and caring activities, with positive impact on family's nutrition and food security. In addition, reduced frequency of collection trips due to greater fuel and stove efficiency can mean less exposure to protection risks. This study estimated amount which rural women would be willing to pay for improved carbon clean cookstoves and analyse determinants of willingness to pay for cook stoves in Ondo State, Nigeria.

\section{Theoretical Framew ork}

\subsection{Consumer Choice}

The environmental benefit of improved cookstoves is based on the classical theory of consumer choice framework in which an individual is assumed to demand goods that maximizes his utility subject to his income. Random utility maximization (RUM) is a concept that provides a link between the statistical model of observed data and an economic model of utility maximization. In valuation problem, the individual considers an environmental improvement (in this case, carbon clean cookstoves) from $\mathrm{Q}^{0}$ to $\mathrm{Q}^{1},\left(\mathrm{Q}^{1}>\mathrm{Q}^{0}\right)$. This is an improvement so that:

$\mathrm{v}\left(\mathrm{Q}^{1}, \mathrm{y}, \epsilon\right) \geq \mathrm{v}\left(\mathrm{Q}^{0}, \mathrm{y}, \epsilon\right)$

(equation 1)

This will result into a positive indoor-air improvement in an individual utility. Respondents are then offered with the cost of improvement and asked if they would be willing to pay for that price. Under the assumption of utility maximization, respondents in a dichotomous choice situation will accepts or rejects a bid amount for the change in the level of provision of a good depending on which choice would have the highest utility.

Response of the respondent is YES if:

$\mathrm{v}\left(\mathrm{Q}^{1}, \mathrm{y}-\mathrm{A}, \epsilon\right) \geq \mathrm{v}\left(\mathrm{Q}^{0}, \mathrm{y}, \epsilon\right)$

And NO if: $\quad \mathrm{v}\left(\mathrm{Q}^{1}, \mathrm{y}-\mathrm{A}, \epsilon\right)<\mathrm{v}\left(\mathrm{Q}^{0}, \mathrm{y}, \epsilon\right)$

(equation 3)

Therefore, the probability that a respondent answers affirmatively is stated as:

$\operatorname{Pr} .(\mathrm{Yes})=\operatorname{Pr} .\left(\mathrm{v}\left(\mathrm{Q}^{1}, \mathrm{y}-\mathrm{A}, \epsilon\right) \geq \mathrm{v}\left(\mathrm{Q}^{0}, \mathrm{y}, \epsilon\right) \quad\right.$ (equation 4$)$

This can be expressed as compensating surplus which satisfies that:

$\mathrm{v}\left(\mathrm{Q}^{1}, \mathrm{y}-\mathrm{CSU}, \epsilon\right)=\mathrm{v}\left(\mathrm{Q}^{0}, \mathrm{y}, \epsilon\right) \quad$ (equation 5)

but,

$\mathrm{CSU}=\mathrm{CSU}\left(\mathrm{Q}^{0}, \mathrm{Q}^{1}, \mathrm{y}, \epsilon\right) \quad$ (equation 6)

Is the respondent maximum willingness to pay for the change from $\mathrm{Q}^{0}$ to $\mathrm{Q}^{1}$ ?

The respondent would answer Yes if the cost is less than his WTP, and No if otherwise;

therefore,

$\operatorname{Pr} .($ Yes $)=\operatorname{Pr} .\left(\operatorname{CSU}\left(\left(\mathrm{Q}^{0}, \mathrm{Q}^{1}, \mathrm{y}, \epsilon\right) \geq \mathrm{A}\right) \quad\right.$ (equation 7)

\subsection{Random Utility Theory}

Random Utility Theory (RUT) is a useful tool which explains individuals' process of choosing from a group of available alternatives. In random utility theory, it is assumed that an individual will derive utility from alternatives. The utility is that an individual will choose the alternative that he/ she derives the highest utility from.

If $A=\left\{A_{1}, \ldots, A_{1}, \ldots A_{N}\right\}$ is the group of alternatives, mutually exclusive for the individual and $X=\left\{X_{1 q}, \ldots, X_{k q}, \ldots, X_{K q}\right\}$ the individual's group of attributes and his alternatives, each of the alternatives has an associated utility $U_{\text {iq }}$ for each of the individuals. 
The Random Utility Theory proposes that such utility has two components: an observable and the measurable $\left(\mathrm{U}_{\mathrm{iq}}\right)$ which is a function of the attributes $\mathrm{X}_{\mathrm{iq}}$ and a stochastic $\left(\varepsilon_{\mathrm{iq}}\right)$, which reflects each individual's preferences, choices, etc., apart from the mistakes regarding measure and observation. The random component explains why individuals with identical characteristics choose different alternatives and certain individuals do not, at first, seems to be more beneficial (McFadden, 1997). It is proposed that:

$\mathrm{U}_{\mathrm{iq}}=\hat{\mathrm{U}}_{\mathrm{iq}}+\varepsilon_{\mathrm{iq}}=\sum_{\mathrm{k}=1}^{\mathrm{k}} \theta X_{\mathrm{iq}}+\varepsilon_{\mathrm{iq}}$

The individual will choose the alternative which maximizes his utility, in other words, the reason why the individual $q$ chooses alternative $\mathrm{A}_{\mathrm{i}}$, is defined as:

$\operatorname{Pi}=\operatorname{Prob}\left(\mathrm{U}_{\mathrm{iq}}>\mathrm{U}_{\mathrm{jq}}\right) \forall \mathrm{Aj} \neq \mathrm{i}$

\section{Materials and Methods}

\subsection{Study Area, Sampling Technique and Data Collection}

The study was carried out in Ondo State, Southwest of Nigeria. The State lies between longitudes $4^{\circ} 30^{\prime}$ and $6^{\circ} 00^{\prime}$ East of the Greenwich Meridian, $5^{\circ} 45^{\prime}$ and $8^{\circ} 15^{\prime}$ North of the Equator. The people live mostly in organized settlements, towns, villages and cities while the people are predominantly peasant farmers cultivating mainly cash and food crops (Ojo, 2000). Primary data were collected through questionnaire administration on the rural farming households. Personal interviews were also used to validate field responses.

A multi-stage sampling technique was used in select final sampling unit of respondents. In the first stage, IleOluji/ Okeigbo, Odigbo and Ondo East Local Government Areas (LGAs) were randomly in the State. In the second stage, four (4) communities were randomly selected using a simple random method (Ile- Oluji Local Government: Bamikemo, Okeigbo, Kajola and Oloruntele; Odigbo Local Government: Odigbo, Oniparaga, Ajegunle and Ajue; Ondo East Local Government: Sasere, Bolorunduro, Igbooja and Ayetoro). In the final stage: fifteen (15) rural households were randomly selected from each of the communities. Of the 180 respondents selected, 178 respondents were analysed for the study.

\subsection{Dichotomous Choice Model Estimation}

The Willingness to Pay (WTP) for improved indoor-air quality was obtained through data collected from responses to the choice tasks which reflect preferences for alternatives as described by the attributes. Such preferences usually vary based on the differences in attributes that define each alternative, and can be used to examine WTP for attribute changes (Adamowicz et al., 1998). The consumer preferences are characterized using a Random Utility Model (RUM).

A RUM is expressed as (McFadden, 1997):

$\mathrm{U}_{\mathrm{ij}}=\mathrm{V}_{\mathrm{ij}}+\varepsilon_{\mathrm{ij}}=\beta^{\prime} \mathrm{X}_{\mathrm{ij}}+\varepsilon_{\mathrm{ij}}$ (equation 10)

Where;

$\mathrm{U}_{\mathrm{ij}}$ is the utility individual i receives from choosing alternative $\mathrm{j}(\mathrm{j} \in \mathrm{J})$

$\mathrm{V}_{\mathrm{ij}}=\mathrm{V}\left(\mathrm{X}_{\mathrm{ij}}\right)$ is "approximated" utility characterized by a vector of observable attributes $X_{\mathrm{ij}}$

$\beta^{\prime}$ is a vector that measures the weights that the individual places on these attributes,

$\varepsilon_{\mathrm{ij}}$ represents all other unobservable and unknown factors and is treated as random

The responses to dichotomous choice WTP questions were analyzed using binary logistic regression model. For this model, the dependent variable is WTP, where WTP $=0$ (if respondent is not willing to pay), and WTP=1 (if respondent is willing to pay a specified bid amount). The significant drivers of WTP was determined using Logit model as commonly used in environmental studies (See Lindberg et al., (1997), Ahtiainen (2007) and Mehrara et al., (2009). This paper analysed how differences in attributes of biomass-burning improved cookstoves explain variation in demand for five important features, namely price, fuel source, flame, cooking time and indoor air pollution.

\section{Results and Discussions}

\subsection{Willingness to Pay Estimates for Improved Cookstove}

The result presented on Tables 1 expressed the sample choice experiment task on the type of improved cookstove, that respondents are willingness to pay for and their choice of types, given some attributes. Respondents were allowed to choose from three varieties of cookstoves as defined by various combinations of product attributes, including brand (Envirofit, KIKE Green and Improved Charcoal cookstove) at a price (\$3000, 3500 and $\$ 2500$ ), fuel type (fuelwood, biofuel and charcoal), flame emitted (Low carbon emission, Negligible carbon emission, Considerable carbon emission), cooking time (Reduced by 50\%, Reduced by $20 \%$, Reduced by 50\%), indoor Air Pollution (Reduced by $82 \%$, Smokeless and odourless, Reduced by 56\%) and label (yes, and no). It should however be noted that a "None" option was available to the respondents (Vermeulen, et al., 2008). Therefore, different four choices were available to the respondents in each choice task. $77.5 \%$ of respondents are willing to pay for improved cookstove while $22.5 \%$ are not willing. Of all respondents willing to pay for cookstoves, $43.8 \%$ are willing to pay for Envirofit, $19.1 \%$ are willing to pay for KIKE Green Cookstove, $14.6 \%$ went for charcoal cookstove while $22.5 \%$ are not willing to purchase any kind of cookstove. 


\begin{tabular}{|c|c|c|c|c|}
\hline & Envirofit & KIKE Green & Charcoal & None \\
\hline Price & N 3000 & N3500 & N2500 & \multirow{5}{*}{$\begin{array}{l}\text { I wouldn't choose } \\
\text { any of these }\end{array}$} \\
\hline Fuel Source & Wood, Crop waste & Bio fuel & Charcoal & \\
\hline Flame & $\begin{array}{c}\text { Low carbon } \\
\text { emission }\end{array}$ & $\begin{array}{c}\text { Negligible } \\
\text { carbon emission }\end{array}$ & $\begin{array}{c}\text { Considerable carbon } \\
\text { emission }\end{array}$ & \\
\hline Cooking time & Reduced by $50 \%$ & Reduced by $20 \%$ & Reduced by $50 \%$ & \\
\hline $\begin{array}{l}\text { Indoor Air } \\
\text { Pollution }\end{array}$ & Reduced by $82 \%$ & $\begin{array}{l}\text { Smokeless and } \\
\text { odourless }\end{array}$ & Reduced by $56 \%$ & \\
\hline
\end{tabular}

Table 1: Results of Sample Choice Experiment Task on Cookstove Types

\subsection{Determinants of Rural Households' Willingness to Pay for Improved Cookstoves}

The estimates from the logistic regression model identified significant drivers of rural households' willingness to pay for improved cookstoves in Table 2. None of the variables were significant at $5 \%$ level, a stepwise logistic regression was however fitted. Stepwise logistic regression is useful for sifting through large numbers of potential independent variables and/ or fine-tuning a model by poking variables in or out. The stepwise option lets you either begin with no variables in the model while proceeding forward (adding one variable at a time), or start with all potential variables in the model and proceed backward (removing one variable at a time).

\begin{tabular}{|c|c|c|c|c|c|}
\hline Variables & $\beta$ & S.E. & Wald & Sig. & $\operatorname{Exp(B)}$ \\
\hline PryOccp & & & 2.578 & .461 & \\
\hline PryOccp(1) & -.237 & .919 & .066 & .797 & .789 \\
\hline PryOccp(2) & -.931 & 1.033 & .812 & .368 & .394 \\
\hline PryOccp(3) & -1.447 & 1.242 & 1.357 & .244 & .235 \\
\hline Age & .024 & .039 & .367 & .545 & 1.024 \\
\hline SEX(1) & .376 & .667 & .318 & .573 & 1.457 \\
\hline FamSize & .295 & .276 & 1.143 & .285 & 1.343 \\
\hline EducLev & -.150 & .311 & .233 & .629 & .861 \\
\hline IncPryOccp & .000 & .000 & .409 & .522 & 1.000 \\
\hline CCCAwrns & 1.496 & 1.290 & 1.346 & .246 & 4.465 \\
\hline FuelAssess & & & 3.074 & .215 & \\
\hline FuelAssess(1) & 1.015 & .579 & 3.074 & .080 & 2.760 \\
\hline FuelAssess(2) & 19.774 & $4.019 \mathrm{E} 4$ & .000 & 1.000 & $3.871 \mathrm{E} 8$ \\
\hline InfoSorce & 2.101 & 1.339 & 2.463 & .117 & 8.175 \\
\hline Constant & -6.879 & 3.982 & 2.985 & .084 & .001 \\
\hline
\end{tabular}

Table 2: Results from Estimates of the Logistic Regression (Stepwise Model)

Backward stepwise logistic regression involves starting with all candidate variables, testing the deletion of each variable using a chosen model comparison criterion, deleting the variable (if any) that improves the model the most by being deleted, and repeating this process until no further improvement is possible. At each step, the variable that is the least significant is removed. This process continues until no non-significant variables remain but backward stepwise regression reached step 8. The result of the backward stepwise regression at step 8 is shown in Table 3 .

In Step 8, the end of the analysis, source of information and family size both have positive coefficients. As family size increases, the willingness to pay for improved cookstove also increases. Source of information is significant at $10 \%$ level, indicating that source of information positively influenced rural women's decision to use improved cookstove. As the means of communicating benefits of improved clean cookstove to rural dwellers changes from institutional to noninstitutional, the willingness to pay for clean cookstove increases. The non-institutional sources include friends, relatives, neighbour while the institutional sources include prints media, radio, and television, among others. The institutional sources are rarely readily available to rural dwellers. Rural households do not usually have the means to acquire print media sources of information while some of them may not be literate enough to read them. Rural women will utilize their low incomes to procure personal essentials. Thus, even if the print media is available gratis, a significant proportion the rural population may still not be able to access the information contained therein (Sikhakhane and Lubbe, 2005).

\begin{tabular}{|c|c|c|c|c|c|c|}
\hline Variables & $\boldsymbol{\beta}$ & S.E. & Wald & df & Sig. & Exp(B) \\
\hline FamSize & .358 & .227 & 2.489 & 1 & .115 & 1.430 \\
\hline InfoSorce* & 2.469 & 1.286 & 3.686 & 1 & .055 & 11.808 \\
\hline Constant & -5.206 & 2.923 & 3.172 & 1 & .075 & .005 \\
\hline
\end{tabular}

Table 3: Estimates of the Backward Stepwise Logistic Regression Model at Step 8

* Significant at $10 \%$ Level 


\subsection{Hypotheses Testing}

Chi square was used to test the hypothesis that there was no significant relationship between rural women's awareness of improved cookstoves and amount they were willing to pay. The cross-tabulation results are presented in Table 4.

\begin{tabular}{|c|c|c|c|c|c|}
\hline \multirow{2}{*}{ Awareness } & \multicolumn{5}{|c|}{ Willingness to Pay for Different Cookstoves } \\
\cline { 2 - 6 } & Envirofit & KIKE Green & Charcoal & None & Total \\
\hline Yes & 44 & 27 & 15 & 20 & 106 \\
\hline No & 34 & 7 & 11 & 20 & 72 \\
\hline Total & 78 & 34 & 26 & 40 & 178 \\
\hline
\end{tabular}

Table 4: Cross Tabulation of Awareness and Willingness to Pay

Pearson Chi-Square $=7.439$ Df $=3$ Asymp. Sig. $(2$-Sided $)=0.059$

The result of the chi square analysis shows that the $\chi 2$ - computed $=7.44$ while the tabulated $\chi 2=6.25$ at 3 degrees of freedom. Given that the $\chi 2$ computed is greater than the tabulated $\chi 2$, the null hypothesis that there is no relationship between awareness and willingness to pay is hereby rejected. The second hypothesis tested the existence of relationship between perceptions of health risks of fuel wood and households' willingness to pay for improved clean cookstoves. Results on Table 5 show the cross-tabulation results of health effect of traditional stoves and willingness to pay. The computed $\chi 2=1.62$ while the tabulated $\chi 2=7.78$ at 4 degrees of freedom. Given that the $\chi 2$ computed is lower than the $\chi 2$ tabulated, the null hypothesis that there is no relationship between health effect of traditional stoves and willingness to pay is hereby accepted.

\begin{tabular}{|c|c|c|c|}
\hline \multirow{2}{*}{$\begin{array}{c}\text { Health Effect of } \\
\text { Traditional Stoves }\end{array}$} & \multicolumn{3}{|c|}{ Willingness to Pay for Carbon Clean Cookstove } \\
\cline { 2 - 4 } & No & Yes & Total \\
\hline No effect & 25 & 73 & 98 \\
\hline Catarrh & 3 & 11 & 14 \\
\hline Cough & 4 & 14 & 18 \\
\hline Eye Irritation & 8 & 39 & 47 \\
\hline Others & 0 & 1 & 1 \\
\hline Total & 40 & 138 & 178 \\
\hline
\end{tabular}

Table 5: Cross Tabulation of Health Effect of Traditional Stoves and Willingness to Pay Pearson Chi-Square $=1.62 \mathrm{Df}=4$ Asymp. Sig. $(2$-Sided $)=0.805$

\section{Conclusion and Policy Implications for Sustainable Development}

The willingness to pay estimate revealed that $77.5 \%$ of the respondents are willing to pay for improved clean cookstoves while $22.5 \%$ are not. Of those willing, it was shown that $43.8 \%$ are willing to buy Envirofit Cookstove simply because they could easily source for wood fuel in their farms. This study has further shown that the formal means of communication such as radio, television, print media, etc may not be as effective as expected in creating the required awareness for the benefits of improved clean cookstoves over traditional stoves. This suggests a need to increase awareness creation on the opportunity cost (health risks) of continual use of traditional cookstoves. The method of awareness creation will play a significant role in the numbers of persons that can be reached and the level of awareness that could be created. The awareness of the potential health risks of the traditional cookstoves was not strong enough to be the motivation for willingness to procure clean cookstoves. Given that, large number of respondents prefers Envirofit cookstove to others, efforts should therefore be mass produce and make it available to rural areas to guarantee a clean, decent and healthy indoor environment. Awareness of the potential health risks of the traditional cookstoves should be made known to the rural dwellers so as to improve the longevity of the residents.

\section{References}

i. Akut, Y.B. (2008). "Some Determinants of House - Hold Energy Consumption in Jimeta. Urbanization, Resource Exploitation and Environmental Stability in Nigeria". Book of Proceedings of the 49th Annual Conference of the Association of Nigerian Geographers (ANG). Joyce Graphics Printers \& Publishers. Pg. 535 \& 537.

ii. American Society of Mechanical Engineers (2009); "ASME General Position Statement on ReducingCarbon Dioxide Emissions Technology and Policy Recommendations and Goals for In the Energy Sector"

iii. Birzer. C. et al (2013); “An Analysis of Combustion from a Top-Lit Up-Draft (TLUD) Cookstove”.Journal Humanitarian Engineering, Vol 2 No 1

iv. Climate Change Summary (2014). "Carbon Neutral Company". Retrieved from http:/ / www.carbonneutral.com

v. Clough L. and Rai K. (2012). "Review of Household Clean Energy Technology for Lighting, Charging and Cooking in East Africa - Kenya and Tanzania". Global Village Energy Partnership (GVEP).

vi. Eleri E., Okechukwu U., and Onuvae P. (2011); “Low-carbon Africa: Nigeria”. International Center for Energy, Environment \& Development. Retrieved from christianaid.org.uk/ low-carbon-africa, (10 thJune, 2014).

vii. Ezzati Mand Baris E. (2007). "Household energy and health in rural china: Lessons and PotentialsforProgram Design". Washington DC: ESMAP, World Bank. 
viii. Global Alliance for Clean Cookstoves (GACC) (2013). "Clean Cookstoves and Fuels Carbon Project. A Catalog of Carbon Offsets for Sale". Retrieved from: http:/ / www.cleancookstoves.org/

ix. Hassan A. (2013). "Energy Need Assessment and Preferential Choice Survey of Rural People in Bangladesh". MSc Thesis, KTH School of Industrial Engineering and Management Energy Technology EGI-2013-030MSC, Division of Energy and Climate studies.

x. International Centre for Energy, Environment \& Development (ICEED) (2013); “Workshop on Taking Stock Clean Cookstoves Design, Production and Testing in Nigeria”, Abuja, April 9, 2013

xi. Ityavyar E.M. \& Thomas T.T. (2013). "Environmental Pollution in Nigeria: The Need for Awareness Creation for Sustainable Development". Journal of Research in Forestry, Wildlife and Environment. Vol 4, No 2

xii. Jingchao Z. and Kotani K. (2010). "The Determinants of Household Energy Demand in Rural Beijing", International University of Japan Research Institute.

xiii. Maconachie, R., Tanko, A. \& Zakariya, M. (2009). "Descending the energy ladder? Oil price Shocks and domestic fuel choices in Kano, Nigeria". Land Use Policy, Vol 26, No 4, Pg 1090-1099.

xiv. Masera O.R., Diaz.R., Berrueta.V. (2005); "From Cookstoves to Cooking Systems: The Integrated Program on Sustainable Household Energy Use in Mexico". Energy for Sustainable Development l. Volume IX No. 11

xv. Menya E., Alokore Y., Ebangu B. O. (2013). "Biogas as an Alternative to Fuelwood for aHousehold in Uleppi SubCounty in Uganda". Agricultural Engineering International: CIGR Journal, Vol. 15, No.1

xvi. McFadden D. (1997). "Measuring Willingness-to-Pay for Transportation Improvements". Retrieved from http:/ / elsa.berkeley.edu/ mcfadden, 14 ${ }^{\text {th }}$ December, 2015

xvii. Momodu I. M. (2013): "Domestic Energy Needs and Natural Resources Conservation: The Case of Fuelwood Consumption in Nigeria". Mediterranean Journal of Socia Sciences, Vol 4, No 8, pp 27 - 3

xviii. Mtega W.P. (2012). "Access to and Usage of Information among Rural Communities: A Case Study of Kilosa District Morogoro Region in Tanzania". The Canadian Journal of Library and Information Practice and Research, Vol 7, No 1

xix. Naibbi I. A and Healey R. G. (2013). 2Northern Nigeria's Dependence on Fuelwood: Insights from Nationwide Cooking Fuel Distribution Data". International Journal of Humanities and Social Science. Vol. 3 No. 17.

xx. Ojo, S. O. (2000). "Factor Productivity in Maize Production in Ondo State, Nigeria". Applied Tropical Agriculture, Vol 5 No 1, pp 57 - 63.

xxi. Sikhakhane B. and Lubbe S. (2005). "Preliminaries into Problems to Access Information - The Digital Divide and Rural Communities". South African Journal of Information Management, Vol. 7, No 3.

xxii. UNDP/WHO (2009); "The Energy Access Situation in Developing Countries: A Review Focusing on the Least Developed Countries and Sub-Saharan Africa. 2009".

xxiii. Vermeulen, B., P. Goos, and M. Vanderbroek. 2008. "Models and Optimal Designs for Conjoint Choice Experiments Including a No-Choice Option." International Journal of Research in Marketing, Volume 25, No 2, pp 94-103.

xxiv. World Bank (2012); Africa Clean Cooking Energy Solutions 